FAME Laboratory, Department of Physical Education and Sport Science, University of Thessaly, Thessaly, Greece

2 Center for International and Regional Studies, Georgetown University, Doha, Qatar

3 Department of Global Public Health and Primary Care, University of Bergen, Bergen Norway

4 Graduate School of Public Policy, Nazarbayev University, Nur-Sultan, Kazakhstan

5 Institute of Policy Studies, Lee Kuan Yew School of Public Policy, National University of Singapore, Singapore

6 Migrant Health Research Group, Institute for Infection and Immunity, St George's, University of London, London, UK

Correspondence to: A D Flouris andreasflouris@gmail.com Cite this as: BMJ 2021;374:n1615 http://dx.doi.org/10.1136/bmj.n1615 Published: 06 August 2021
MIGRANT HEALTH

\section{Improving the evidence on health inequities in migrant construction workers preparing for big sporting events}

Data suggest migrant construction workers are at risk of work related ill health, injury, and death, but better evidence to inform policy making and improve their health is needed, say Andreas Flourisand colleagues

Andreas D Flouris, ${ }^{1}$ Zahra Babar, ${ }^{2}$ Leonidas G loannou, ${ }^{1}$ Kristine H Onarheim, ${ }^{3}$ Kai H Phua, ${ }^{4,5}$ Sally Hargreaves ${ }^{6}$

To host big sporting events such as the Olympic Games and the Féderration Internationale de Football Association (FIFA) World Cup, countries undertake large infrastructure projects, including building new stadiums and extending public transportation. Hundreds of thousands of migrant workers a year are needed, often quickly and for a short time. Given local constraints in supply, many such jobs are filled by low skilled, low waged migrant labourers.

Recent sustained media and public interest in the conditions of these migrant workers, particularly during the covid-19 pandemic, has highlighted their poor and overcrowded living and working conditions. ${ }^{1}$ In addition to harsh working and living conditions, marginalised and exploited migrants labourers-in the construction sector but also in many other sectors including manufacturing, services, domestic work, and healthcare-often face socioeconomic inequalities, barriers to health and vaccination services in host countries, and limited rights, all of which affect their physical and mental health. They may be more susceptible to infectious disease because of their living and working conditions as well as to a higher burden of some infections (eg, tuberculosis) in the countries from which they originate. They may also be underimmunised. ${ }^{1}$ Yet a steady flow of migrant workers in search of work opportunities continues from low and medium income countries to high income countries.

Limited research has explored the occupational, health, and social conditions that migrant workers have experienced, particularly since the year 200o..$^{2-14}$ To inform international and regional dialogue and policy making, we need to understand better the health needs, social situations, and occupational hazards of such workers.

\section{Evidence on health needs}

Data from systematic reviews and meta-analyses show that low skilled migrant labourers in general are at considerable risk of work related ill health and injuries. ${ }^{15}{ }^{16}$ Migrant labourers are reported to have various psychiatric and physical morbidities, while workplace accidents and injuries-including falls from heights, fractures and dislocations, and ocular injuries-are relatively common. ${ }^{16}$ A systematic review of immigrant populations and their work and occupational health showed that these populations had a high risk of occupational injuries and illnesses. ${ }^{15}$

Grey literature and news articles have highlighted that low skilled, low waged migrant workers employed in construction for big sporting events face increased health risks, injuries, and higher death rates. ${ }^{17-19}$ To assess the mortality risk associated with such construction work, we used national or regional data to summarise total occupational fatalities and total labour force reported for the seven years before and the one year after the summer Olympic Games between 1992 and 2016-Barcelona 1992,, ${ }^{21}$ Atlanta 1996, ${ }^{22} 23$ Sydney 2000, ${ }^{2425}$ Athens 2004, ${ }^{20} 25$ London 2012, ${ }^{2526}$ and Rio de Janeiro $2016^{2527}$ : data for Beijing 2008 were not available (fig 1 ). The data show a substantial increase in the incidence of occupational fatalities in the five years before each of these games opened. 

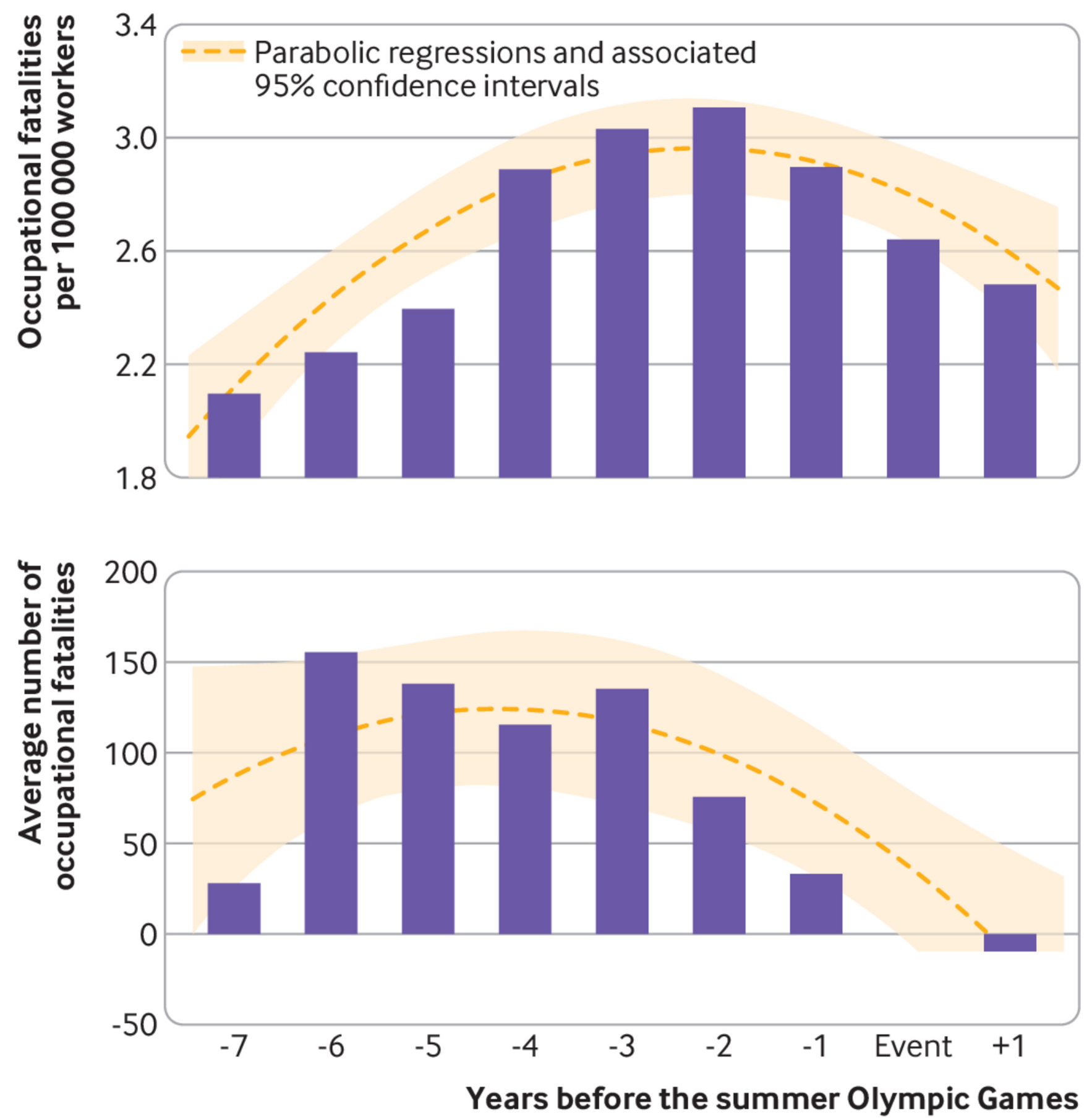

Fig 1 | Deaths in labourers before, during, and after six summer Olympic Games. Summarised national data for the summer Olympic Games, Barcelona $1992,{ }^{20}$ Sydney $2000,{ }^{24}$ Athens $2004,{ }^{20}$ London 2012, ${ }^{26}$ and Rio de Janeiro 2016, ${ }^{27}$ as well as state data for Atlanta $1996^{22}$ (data for Beijing 2008 were not available). Number of fatal occupational injuries calculated using total labour force data from published sources for Spain (Barcelona 1992) ${ }^{21}$ and the State of Georgia (Atlanta 1996) ${ }^{23}$ and from the World Bank ${ }^{25}$ for all other Olympic Games.

Ethnographic studies have shown that the inability of labour migrants to adequately speak or understand the working language or languages of their managers increases their vulnerability. ${ }^{513}$ Their temporary stay in the host country and their often unrecognised contribution to the big sporting event undermine their wellbeing, creating an overwhelming sense of disillusionment and disappointment. ${ }^{78}$ Reports from the 2010 Commonwealth Games in Delhi ${ }^{8}$ describe violations of workers' rights as well as negligence of safety standards and equipment maintainance. ${ }^{12}$

The prevalence of sexually transmitted infections was investigated in workers employed at construction sites of the 2014 FIFA World Cup in Rio de Janeiro ${ }^{3}$ and the 2012 summer Olympic Games in London. ${ }^{11}$ In both cases, studies reported a low prevalence of sexually transmitted infections and risk factors for infection. ${ }^{311}$ To further improve the prevention of sexually transmitted infections 
among labour migrants, the authors emphasised the importance of educational campaigns that deal with specific risk factors that emerged from the studies, including multiple sex partners over a short period and the use of sex worker services, as well as tackling family separation as an important risk factor. ${ }^{3}$ Studies are needed to investigate unexplored questions of whether and how big sporting events affect the sex worker industry, and the extent to which targeted public health interventions in this area could be needed.

Big sporting events organised in hot regions expose migrant workers at the construction sites to hazards related to heat. ${ }^{4829}$ Studies on labour migrants at a construction site for the 2022 FIFA World Cup in Doha reported that people working outdoors in the sun spend most of their shift under high or extreme heat stress. ${ }^{40}$ The same research reported that the health risks of these workers were reduced in workplaces that implemented simple evidence based heat mitigation strategies, including providing shaded areas and requiring workers to carry water bottles throughout their shifts, worker educational programmes, and annual medical checks. 430 This evidence led to amendments to legislation in Qatar to protect workers further from occupational heat stress.

This research also reported that workers were at risk of insufficient sleep, particularly those working during night hours. ${ }^{4}$ Night shifts are often used to accelerate progress on building projects, such as in the time-bound construction of facilities for big sporting events. While some aspects of work improve during night shifts, such as commuting, productivity (through reduced idle machinery time), and reduction in exposure to occupational heat stress, the unfavourable effects of night shifts on the safety, productivity, and health of construction labourers have also been reported. ${ }^{31}$

Poor work practices, by management and individual workers, as well as time pressure to complete work, contributed to increased health and safety risks in the preparations for the 2004 summer Olympic Games in Athens ${ }^{6}$ and the 2022 FIFA World Cup in Qatar. ${ }^{10}$ The lack of experience often seen in low skilled migrant workers employed in construction ${ }^{32}$ and the pressure to complete tasks increase the risk of injuries. ${ }^{610}$ These concerns can be effectively managed by increasing inspection on construction sites, which highlights the role that governments and labour inspectors can play in preventing deaths and injuries among construction workers. ${ }^{6} 10$

\section{Strengthening the evidence to improve health}

Important research gaps exist about the health and social needs of migrant construction workers. Such research is needed to tackle the causes of morbidity and mortality in these workers and to allow meaningful policy responses that develop, implement, and evaluate targeted multilevel interventions to reduce injury and deaths in migrant construction workers and improve their health.

To understand the factors affecting the health, social, and occupational risks faced by migrant workers employed on big sporting projects, longitudinal and comparative research is needed on the health conditions and outcomes of these workers in different countries and regions, and covering all phases of

migration-premigration phase, movement phase, arrival and integration phase, and return phase. For example, research is needed on healthcare services available to migrant workers before leaving their home country, in the host country, and on their return home, including access to screening, preventive healthcare, and vaccination. This information is needed to better understand the factors that impede or facilitate migrant workers' access to public or private health systems for acute needs during their stay in the host country and the obligations of governments and private companies that manage their stay. ${ }^{5}{ }^{33}$ Much attention has been given recently to the extent to which migrant populations in high income countries will have access to covid-19 vaccines, with the World Health Organization highlighting low skilled labour migrants as a priority group. ${ }^{34} 35$ Because family separation creates health risks for the people who migrate ${ }^{35732}$ and the people left behind, 3637 it is vital also to collect data on the health effects on the families of migrant workers.

The intermittent and short term nature of these events makes it difficult for researchers to access study participants, maintain a sustained interest in the topic, and carry out empirical studies across multiple construction sites globally and at events that occur years or decades apart. Many labour migrants get only short term visas tied to short term contracts before they return home. Researchers may have poor links with the countries of origin of the migrant workers, and many such workers are excluded from national health systems of origin or host countries. ${ }^{38}$ This makes it hard to track the health status and health needs before arrival, during the period of migration and work in the host country, and in follow-up after they return home.

Researchers have tried different approaches to manage these problems. In some cases (see fig 1, for example), researchers have used total municipal, regional, or national data covering the period before or during a sporting event. ${ }^{610}$ Such studies assume that year on year changes in reported health outcomes reflect the effect of the big sporting event because their data cover a relatively confined geographical region. The relevance of such studies for policy is limited, but they may be useful in the absence of more specific evidence.

The first step for strengthening the evidence and improving health is to improve data collection by establishing common data collection protocols that enable countries to report on health needs, illness, injuries, and deaths of migrant construction wokers. ${ }^{1439}$ Researchers have previously called for the use of a common framework ${ }^{15}{ }^{16}$ that adopts existing methods including the International Standard Classification of Occupation $\mathrm{s}^{40}$ and the International Classification of Diseases. ${ }^{41}$ As covid-19 vaccine rollout continues, it will be important to monitor vaccine uptake in these groups and ensure that they are included in the national response of the host country..$^{42}$

When it is possible to anonymise data, existing public and private data on the health of migrant labourers should be used to better understand their health risks and the effect of social conditions on their health-for example, the recent disproportionate effect of covid-19 on migrant workers in overcrowded accommodation. ${ }^{1}$ Retrospective analyses of national datasets and datasets of private companies could examine health needs, injuries, and deaths. Disaggregated data can help understand risk that may vary, for example, by type of labour, country of origin, age, and sex. The sex aspect of labour migration is unexplored 43 but relevant. Migrant labourers working on construction sites for big sporting events are mostly men, while workers in service sectors, such as in venue facilities, are largely women.

The ethical implementation of new methods of data collection, such as using electronic data and smartphones, and strengthening reporting by contractors and governments can allow longitudinal studies on the health of labour migrants to be conducted. Public authorities are beginning to use crowdsourcing initiatives to attract software developers to tackle the health problems of construction workers. The smartphone applications and contact tracing solutions tested recently in large construction sites in Singapore are one example of many such attempts. ${ }^{44}$ It is important to ensure that technology assists and empowers migrant labourers and facilitates 
the collection of useful and accurate data, and that these data are used and managed safely, transparently, and ethically.

In addition, qualitative and ethnographic studies are needed to assess the unique experiences of migrant labourers along their journeys, as well as their views and concerns. These insights are important to understand the factors that impede and facilitate healthy migration in order to improve the health and wellbeing of low skilled, low waged labour migrants employed on short term contracts far from home.

Host countries and stakeholders in big sporting events, including FIFA and the International Olympic Committee, need to research models of best practice that ensure health and safety in the workplace and access to health, vaccination, and welfare services. They also need to define minimum standards for living and working conditions for migrant workers.

Finally, governments, policy makers, and contractors should call for, commission, and fund research to improve policies on occupational health and safety for migrant construction workers. They need to assume their responsibility to improve the health outcomes in these groups and meet their obligations under their commitment to the United Nations sustainable development goals to "leave no-one behind" and universal health coverage initiatives to ensure a minimum standard of healthcare for all. Furthermore, host countries and stakeholders should identify gaps in, and barriers to, access to healthcare and vaccinations to allow evidence based policy making and ensure accessible, affordable, and appropriate healthcare and insurance coverage to meet the needs of migrant workers.

These steps to improve health data collection and exchange of research best practices in labour migration and health could have additional benefits-for example, improving our understanding of the health related experiences of migrant domestic workers and other low skilled migrant workers living in high income countries-and may lead to improvements in wider policy. In addition, research comparing different contexts and groups of construction workers and other migrant workers could identify common approaches to improving living and working conditions and health outcomes.

These research priorities build on previous calls ${ }^{45} 46$ for the development of a global research agenda on labour migration and health. Common frameworks, terminology, and methods are needed and the lack of comprehensive data on the health and wellbeing of migrant workers in all phases of migration and their families must be tackled. Low skilled, low waged migrant labourers working in construction for big sporting events may provide the opportunity to make progress on this agenda given the typically shorter duration of their migration cycle.

Countries, international sports organisations (such as the IOC and FIFA), and industry stakeholders rely on migrant construction workers. Governments and private companies have a responsibility and obligation to facilitate their stay. ${ }^{5633447}$ Governments of host countries should develop guidance for sports organisations and industry stakeholders on supporting data collection to assess rates of occupational injury, ill health, and death for migrant workers before, during, and after large sporting events to generate evidence to improve the health and wellbeing of these workers.

\section{Key recommendations}

- Research is needed to better understand morbidity and mortality in migrant workers to enable evidence based policy to improve their health

- Organisations and companies concerned with the preparation of big sporting events (including IOC and FIFA) and host governments must do more to promote research, policies, and practices to improve health and safety in the workplace

- Minimum standards should be defined for living and working conditions for migrant workers, including access to health, vaccination, and welfare services

Contributors and sources: ADF and LGI have studied and reported widely on the impacts of environmental factors on health and the ability to work; ZB is an expert in migration and labour policies, and citizenship; $\mathrm{KHO}$ is an expert in global health priority setting and policy making, including on migration health; KHP has studied and reported widely on the economics of health, including healthcare to workers; SH is an expert in migrant health with a specific focus on vaccination and COVID-19. SH is the guarantor of the article.

Provenance and peer review: Commissioned; externally peer reviewed.

This article is part of a series commissioned by The BMI for the World Innovation Summit for Health (WISH). The BM/peer reviewed, edited, and made the decisions to publish. The series, including open access fees, is funded by WISH.

Competing interests: We have read and understood BMJ policy on declaration of interests and declare the following interests. ADF and LGI are supported by the European Union's Horizon 2020 research and innovation programme (project HEAT-SHIELD; Grant agreement No 668786). SH is funded by the NIHR (NIHR Advanced Fellowship NIHR300072) and the Academy of Medical Sciences (SBF005\1111) and acknowledges the support of the ESCMID Study Group for Infections in Travellers and Migrants.

Hayward SE, Deal A, Cheng C, etalESCMID Study Group for Infections in Travellers and Migrants (ESGITM). Clinical outcomes and risk factors for COVID-19 among migrant populations in high-income countries: a systematic review. J Migr Health 2021;3:100041. doi: 10.1016/j.jmh.2021.100041. pmid: 33903857

2 Bell N, Powell C, Sykes P. Securing the well-being and engagement of construction workers: an initial appraisal of the evidence. In: Raidén AB, Aboagye-Nimo E, eds. Proceedings of the 31st annual ARCOM conference, 7-9 September 2015. Association of Researchers in Construction Management, 2015:489-98.

3 Bottecchia M, Miguel JC, da Silva EF, Ginuíno CF, Souza MT. Screening for hepatitis B virus in Maracanã workers. Braz I Infect Dis 2015;19:100-1 doi: 10.1016/j.bjid.2014.08.006. pmid: 25307679

4 Flouris AD, loannou LG, Dinas CD, etal. Assessment of occupational heat strain and mitigation strategies in Qatar - key findings. International Labour Organization, 2019.

5 Gato LG, Salazar NB. Constructing a city, building a life: Brazilian construction workers' continuous mobility as a permanent life strategy. Mobilities 2018;13:733-45. doi: 10.1080/17450101.2018.1466504

6 Katsakiori P, Manatakis E, Goutsos S, Athanassiou G. Factors attributed to fatal occupational accidents in a period of 5 years preceding the Athens 2004 Olympic Games. Int J Occup Saf Ergon 2008;14:285-92. doi: 10.1080/10803548.2008.11076766 pmid: 18954538

7 Mohammad R, Sidaway JD. Shards and stages: migrant lives, power, and space viewed from Doha, Qatar. Ann Assoc Am Geogr 2016;106:1397-417. doi: 10.1080/24694452.2016.1209402

8 PUDR Team. Violation of workers' rights at the Commonwealth Games construction site. Econ Polit Wkly2009;24:10-2.

9 Rombaldi M. The 2014 World Cup and the construction workers: global strategies, local mobilizations. Lat Am Perspect 2019;46:53-65doi: 10.1177/0094582X19842837

10 Senouci A, Al-Abbadi I, Eldin N. Safety improvement on building construction sites in Qatar. Procedia Eng 2015;123:504-9doi: 10.1016/j.proeng.2015.10.102

11 Shanmugaratnam S, Horne P, Coyne KM. Olympic outreach: testing for sexually transmitted infections in construction workers. Int J STD AIDS 2012;23:659-60. doi: 10.1258/ijsa.2012.012033 pmid: 23033522

12 Sun Y, Fang D, Wang S, etal. Safety risk identification and assessment for Beijing Olympic venues construction. J Manage Eng 2008;24:40-7doi: 10.1061/(ASCE)0742-597X(2008)24:1(40)

13 Theodoropoulou I. Blue-collar workplace communicative practices: a case study in construction sites in Qatar. Lang Policy 2020;19:363-87doi: 10.1007/s10993-019-09518-z

14 Waterman L. London 2012: occupational health in the construction programme. J R Soc Promot Health 2007;127:113-8. doi: 10.1177/1466424007077343 pmid: 17542423

15 Ahonen EQ, Benavides FG, Benach J. Immigrant populations, work and health--a systematic literature review. Scand I Work Environ Health 2007;33:96-104. doi: 10.5271/sjweh.1112. pmid: 17460797

16 Hargreaves S, Rustage K, Nellums LB, etal. Occupational health outcomes among international migrant workers: a systematic review and meta-analysis. Lancet Glob Health 2019;7:e872-82 doi: 10.1016/S2214-109X(19)30204-9. pmid: 31122905 
17 Watts J. Olympic organisers put deadlines ahead of lives, claims Rio labour inspector. Guardian 2016 Jul 28. https://www.theguardian.com/sport/2016/jul/28/olympic-games-deadlines-liveschief-inspector-labour

18 Associated Press. Tokyo Olympic stadium worker's death follows 190 hours of overtime in month. Guardian 2017 Oct 11. https://www.theguardian.com/sport/2017/oct/11/tokyo-olympics-2020stadium-worker-death-190-hours-overtime-one-month

19 Pattisson P. Qatar's workers are at risk of heat stress for half the day during summer, finds UN. Guardian 2019 Oct 15. https://www.theguardian.com/global-development/2019/oct/15/qatarsworkers-are-at-risk-of-heat-stress-for-half-the-day-during-summer-finds-un

20 European Health Information Gateway. Deaths due to work-related accidents per 100000.2018 https://gateway.euro.who.int/en/indicators/hfa_456-4070-deaths-due-to-work-related-accidentsper-100-000/

21 Toharia L. Employment Patterns in Spain between 1970 and 2001. Int J Polit Econ2000;30:82-98 doi: 10.1080/08911916.2000.11644012

22 US Bureau of Labor Statistics. Fatal occupational injuries by selected characteristics, 1992-2002. https://www.bls.gov/iif/oshwc/cfoi/all_worker_1992-2002.xlsx

23 Beta Labs BLS. Labor force, Georgia. United States Department of Labor, 2021. https://beta.bls.gov/dataViewer/view/timeseries/LASST130000000000006

24 Gunby P. How bad is the state of occupational fatalities in New Zealand?N ZJ Employ Relat 2011;36:35-51. doi:doi: 10.3316/informit.473254132410908

25 The World Bank. Labor force, total. 2021. https://data.worldbank.org/indicator/SL.TLF.TOTL.IN

26 Health and Safety Executive. Fatal injuries in Great Britain. 2020. https://www.hse.gov.uk/statistics/fatals.htm

27 Ministério da Saúde. Vigilância em saúde no Brasil 2003/2019: da criação da Secretaria de Vigilância em Saúde aos dias atuais [Portuguese]. Brasil, 2019.

28 DeFilippis J, Martin N, Bernhardt A, etal. On the character and organization of unregulated work in the cities of the United States. Urban Geogr 2009;30:63-90doi: 10.2747/0272-3638.30.1.63

29 Sönmez S, Apostolopoulos Y, Tran D, Rentrope S. Human rights and health disparities for migrant workers in the UAE. Health Hum Rights 2011;13:E17-35.pmid: 22773029

30 Ioannou LG, Mantzios K, Tsoutsoubi L, etal. Occupational heat stress: multi-country observations and interventions. Int J Environ Res Public Health 2021;18:6303doi: 10.3390/ijerph18126303

31 Jun DH, El-Rayes K. Optimizing the utilization of multiple labor shifts in construction projects. Autom Construct 2010;19:109-19doi: 10.1016/j.autcon.2009.12.015

32 Abdul-Aziz A-R. Foreign workers and labour segmentation in Malaysia's construction industry. Construct Manag Econ 2001;19:789-98doi: 10.1080/01446190110072022

33 Millward P. World Cup 2022 and Qatar's construction projects: relational power in networks and relational responsibilities to migrant workers. Curr Sociol 2017:65:756-76doi: 10.1177/0011392116645382

34 ECDC. Reducing COVID-19 transmission and strengthening vaccine uptake among migrant populations in the EU/EEA. European Centre for Disease Prevention and Control, 2021. https://www.ecdc.europa.eu/sites/default/files/documents/covid-19-reducing-transmission-andstrengthening-vaccine-uptake-in-migrants.pdf

35 WHO. WHO SAGE roadmap for prioritizing uses of COVID-19 vaccines in the context of limited supply. World Health Organization, 2020. https://www.who.int/publications/i/item/who-sageroadmap-for-prioritizing-uses-of-covid-19-vaccines-in-the-context-of-limited-supply

36 Knipe D, Lambert H, Pearson M, etal. Are left-behind families of migrant workers at increased risk of attempted suicide? A cohort study of 178,000+ individuals in Sri Lanka. BMC Psychiatry 2019;19:25. doi: 10.1186/s12888-018-2000-8. pmid: 30646952

37 Lakshman RWD, Perera S, Sangasumana RP. The children left behind by international migrants from Sri Lanka: victims or beneficiaries of globalization? In: Veale A, Donà G, eds. Child and youth migration. Palgrave Macmillan, 2014:162-85. doi: 10.1057/9781137280671_8

38 Asanin J, Wilson K. "I spent nine years looking for a doctor": exploring access to health care among immigrants in Mississauga, Ontario, Canada. Soc Sci Med 2008;66:1271-83. doi: 10.1016/j.socscimed.2007.11.043. pmid: 18194831

39 Adsul BB, Laad PS, Howal PV, Chaturvedi RM. Health problems among migrant construction workers: a unique public-private partnership project. Indian J Occup Environ Med 2011;15:29-32. doi: 10.4103/0019-5278.83001. pmid: 21808498

40 ILO. International standard classification of occupations. International Labour Organization, 2010 http://www.ilo.org/public/english/bureau/stat/isco/

41 WHO. International classification of diseases, 11th revision (ICD-11). World Health Organization, 2018. https://icd.who.int/en

42 Bartovic J, Datta SS, Severoni S, D’Anna V. Ensuring equitable access to vaccines for refugees and migrants during the COVID-19 pandemic. Bull World Health Organ 2021;99:3-3A. doi: 10.2471/BLT.20.267690. pmid: 33658728

43 Onarheim KH, Egli-Gany D, Aftab W. Occupational health outcomes among international migrant workers. Lancet Glob Health2019;7:e1614. doi: 10.1016/S2214-109X(19)30391-2. pmid: 31708138

44 Chee K. Workers scan face with mobile app to find out if they are well. The Straits Times 2021 Apr 27. https://www.straitstimes.com/tech/tech-news/workers-scan-face-with-mobile-app-tofind-out-if-they-are-well

45 Hanefeld J, Vearey J, Lunt NResearchers on Migration, Mobility and Health Group. A global research agenda on migration, mobility, and health. Lancet 2017;389:2358-9.

doi: 10.1016/S0140-6736(17)31588-X. pmid: 28635599
46 Wickramage K, Vearey J Zwi AB, Robinson C, Knipper M. Migration and health: a global public health research priority. BMC Public Health 2018;18:987.

doi: 10.1186/s12889-018-5932-5. pmid: 30089475

47 Onarheim KH, Phua KH, Babar ZR, Flouris AD, Hargeaves S. Health and social needs of migrant construction workers for big sporting events. BMJ2021;374:n1591. doi: 10.1136/bmj.n1591

This is an Open Access article distributed in accordance with the Creative Commons Attribution Non Commercial (CC BY-NC 4.0) license, which permits others to distribute, remix, adapt, build upon this work non-commercially, and license their derivative works on different terms, provided the original work is properly cited and the use is non-commercial. See: http://creativecommons.org/licenses/by$\mathrm{nc} / 4.0 /$ 